\title{
Los MorTeros: unA APROXIMACIÓN AL PROCESO DE FORMACIÓN DE UN MONTÍCULO PRECERÁMICO COSTERO
}

\author{
Ana Cecilia Mauricio Llonto ${ }^{a}$
}

\begin{abstract}
Resumen
Los Morteros es un sitio arqueológico Precerámico (5700-5000 cal AP), que tiene forma de montículo escalonado (200 m $\times 200 \mathrm{~m} \times 15 \mathrm{~m}$ ) y está cubierto de arena eólica. Este sitio se ubica al borde de una línea se playa fósil, sobre una llanura aluvial denominada Pampa de las Salinas, en la margen sur del valle bajo de Chao, costa norte del Perú. Los Morteros fue descubierto en 1976 por Mercedes Cárdenas y su equipo de investigación, quienes identificaron a este montículo como una duna fosilizada que habia sido utilizada como zona funeraria por las poblaciones precerámicas de la zona. Nuevas excavaciones intensivas en este montículo, realizadas desde el año 2012 han descubierto el carácter artificial del monticulo y sucesivas fases de ocupación, las que incluyen arquitectura monumental. El enfoque geoarqueológico empleado en las diversas temporadas de investigación en Los Morteros, nos ha permitido reconstruir el proceso de formación de este sitio, donde su ubicación, medio ambiente y cronología jugaron un papel relevante. La continua y dinámica ocupación de Los Morteros hace de este sitio un lugar clave para entender los procesos involucrados en el desarrollo de la arquitectura monumental en los Andes.
\end{abstract}

Palabras clave: Geoarqueología, formación de sitio, precerámico, cronología, medio ambiente.

Abstract

\section{LOS MORTEROS: AN APROXIMATION TO THE FORMATION PROCESS OF A PRECERAMIC COASTAL MOUNTH}

Los Morteros is a mound-shape preceramic (5700-5000 cal AP) archaeological site of large dimensions (200 $\mathrm{m} x$ $200 \mathrm{~m} \times 12 \mathrm{~m}$ ) covered with eolian sand. This site is located on the edge of a paleoshoreline, over an alluvial plain called Pampa de las Salinas, lower Chao Valley of the northern coast of Peru. Los Morteros was discovered in 1976, by an archaeological research team led by Mercedes Cárdenas. This research identified this site as a natural feature (dune) that was used by local preceramic populations as a funerary area. New archaeological research at this site since 2012 has discovered the artificial nature of this site and has recorded several phases of occupation which include the construction of monumental architecture. The geoarchaeological approach of this research has allow us to reconstruct the formation process of this site, where its location, environment, and chronology have played a critical role. The continuous and dynamic occupation of Los Morteros made this site a key place to understand the processes involved in the development of monumental architecture in the Andes.

Keywords: Geoarchaeology, site formation, preceramic, chronology, environment.

a https://orcid.org/0000-0002-7293-6233 Pontificia Universidad Católica del Perú, Departamento de Humanidades, Especialidad de Arqueología. cecilia.mauricio.pucp.edu.pe 


\section{Introducción}

El sitio Los Morteros se ubica en la margen sur del valle bajo del río Chao, departamento de La Libertad, costa norte de Perú, aproximadamente a 9 kilómetros al sur del distrito de Chao. Este sitio fue descubierto en 1976, cuando el proyecto arqueológico Elaboración de una Cronología para el Uso de Recursos Marinos en el Antiguo Perú, liderado por la doctora Mercedes Cárdenas, realizó exploraciones intensivas en el valle y registró 183 asentamientos arqueológicos, que constituyen casi la totalidad de los sitios que hoy se conocen en Chao (Cárdenas 1976). Las exploraciones de Cárdenas y su equipo en el valle bajo de Chao, incluyeron el área denominada Pampa de las Salinas, en la margen sur, donde registraron más de 20 asentamientos, pertenecientes al Precerámico, realizando excavaciones en siete de ellos (Cárdenas 1976, 1999). Entre los sitios descubiertos y excavados por este proyecto se encuentra Las Salinas de Chao (sitio 10 en el inventario de Cárdenas 1976), el sitio más extenso de la zona ( $\sim 12$ hectáreas) y que exhibe arquitectura monumental temprana fechada en cal. 4200-3000 AP (Cárdenas 1976; Alva 1986; Mauricio et al. 2021). Otro sitio descubierto por Cárdenas y su equipo fue Los Morteros (sitio 7 en el inventario de Cárdenas 1976), en el cual se realizaron excavaciones en 12 pozos de prueba que alcanzaron una profundidad máxima de 1 metro.

Cárdenas y su equipo identificaron a Los Morteros como «un promontorio, aparentemente natural, de arena fina y suelta, de 15 metros de altura y 70 por 50 metros aproximadamente» (Cárdenas 1976: 40). Esta descripción obedece a los hallazgos que obtuvieron en las excavaciones de los pozos de prueba, ubicados principalmente en las partes más altas del montículo, donde los entierros humanos registrados se encontraban dentro de capas con restos de fauna marina, morteros de piedra y manos de moler (Cárdenas 1999).

En este artículo se presenta una aproximación a la reconstrucción del proceso de formación del montículo Los Morteros. Se trata de una reconstrucción preliminar pues aún resta por excavar los depósitos más profundos del montículo y, consecuentemente, obtener fechados radiocarbónicos de estos depósitos. Este trabajo representa un aporte al entendimiento de la formación de montículos costeros, pero principalmente, al entendimiento del registro arqueológico y la cronología de formación de un sitio que incluye arquitectura monumental precerámica en diferentes fases de ocupación. El entendimiento de los procesos de formación de los sitios con arquitectura monumental durante el Periodo Precerámico, así como su cronología, son temas centrales en la discusión acerca del surgimiento de la monumentalidad y la complejidad social en los Andes Centrales (Pozorski y Pozorski 1990; Quilter 1991; Shady et al. 2001; Haas y Creamer 2006; Dillehay et al. 2012), pues nos permite acercarnos a los procesos sociales y las dinámicas medioambientales de estos.

\section{Medio ambiente y geomorfología de Pampa de las Salinas}

Pampa de las Salinas es un área localizada en la margen sur del valle bajo de Chao, costa norte del Perú (Fig. 1). Esta es una zona relativamente aislada del valle, localizada a aproximadamente $9 \mathrm{~km}$ al suroeste del distrito de Chao. Se trata de un área de aproximadamente 25 kilómetros cuadrados, delimitada por estribaciones andinas volcánico-sedimentarias: los cerros Coscomba y Salinas, al este y al sur, respectivamente y los cerros Jaime al norte.

Geomorfológicamente, Pampa de las Salinas se compone principalmente de dos formaciones bien diferenciadas. Hacia el oeste, abarcando la mayor parte de esta zona, se ubica una bahía seca, delimitada por una línea elevada de playa fósil, que alcanza 3 metros de altura en promedio. Hacia el este de la bahía seca, se extiende una llanura aluvial, sobre la línea de playa fósil, que tiene una altura mayor en relación a la bahía seca y está formada por los depósitos aluviales producto de la meteorización de los cerros que rodean y delimitan esta área (Fig. 2A). Canales aluviales del Pleistoceno Tardío al Holoceno Medio recorren la pampa, decreciendo en antigüedad conforme se acercan a la línea de playa fósil (Fig. 2B). 


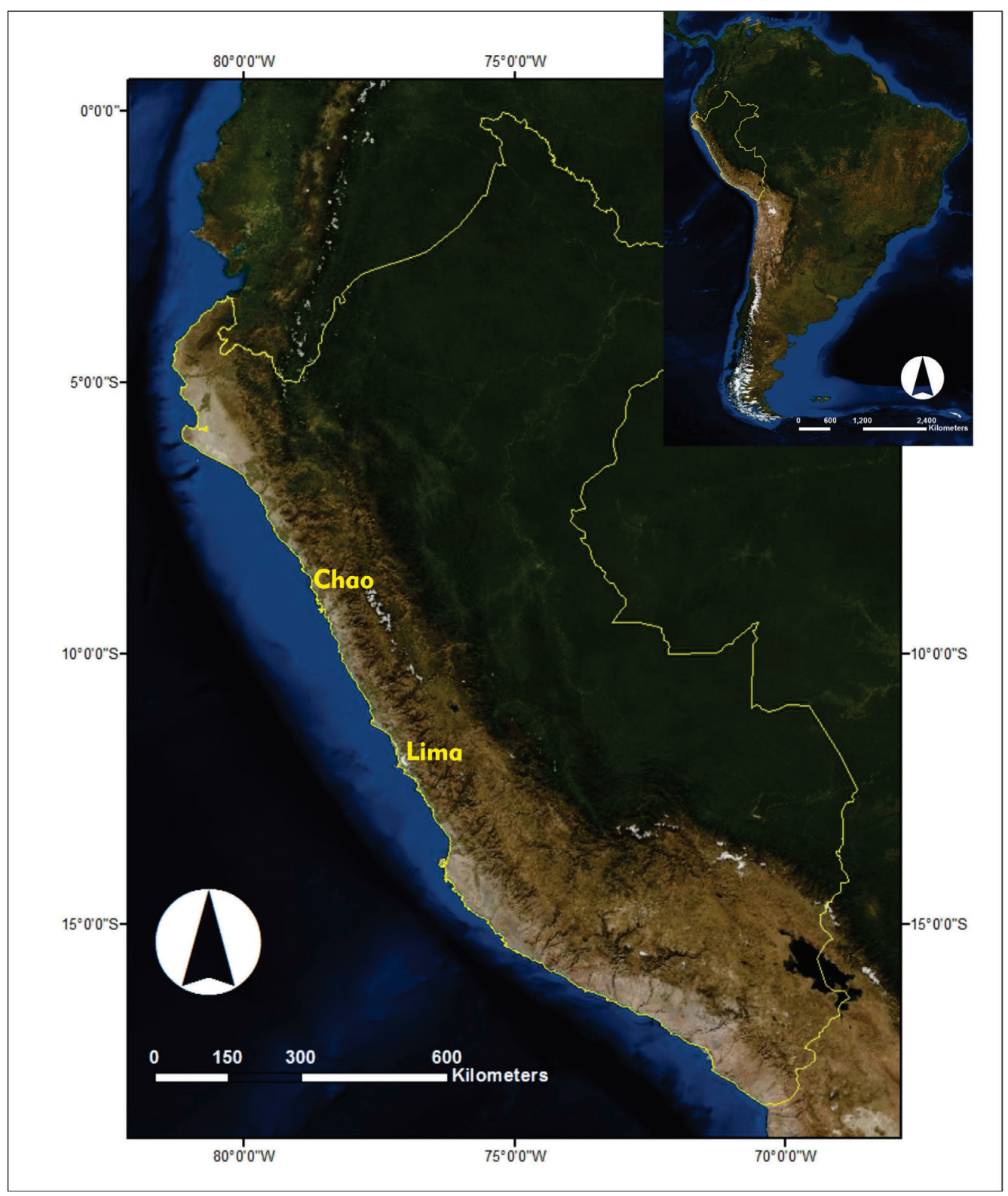

Figura 1. Ubicación del valle de Chao en el territorio peruano (elaborado por: Ana Cecilia Mauricio).

Tanto la llanura (pampa), como la bahía seca están cubiertas por depósitos de arena, los cuales, al interior de la bahía seca, forman hasta cuatro campos de dunas barjanes que se alinean de suroeste a noreste, siguiendo el patrón de los vientos costeros. Algunas de estas dunas sobrepasan los 10 metros de altura (Fig. 2C).

Pampa de las Salinas se caracteriza por su aridez, no hay vegetación en la superficie, a excepción del sector noroeste de la bahía seca, donde se pueden observar remanentes de vegetación de humedales y grama salada en las secciones más próximas al río y al mar. Desde la línea de playa fósil, el océano se encuentra a aproximadamente 4 kilómetros y el río Chao a 7 kilómetros. No hay poblaciones modernas que ocupen la zona. Las tierras de Pampa de las Salinas pertenecen a dos 
Pampa de las Salinas, valle de Chao
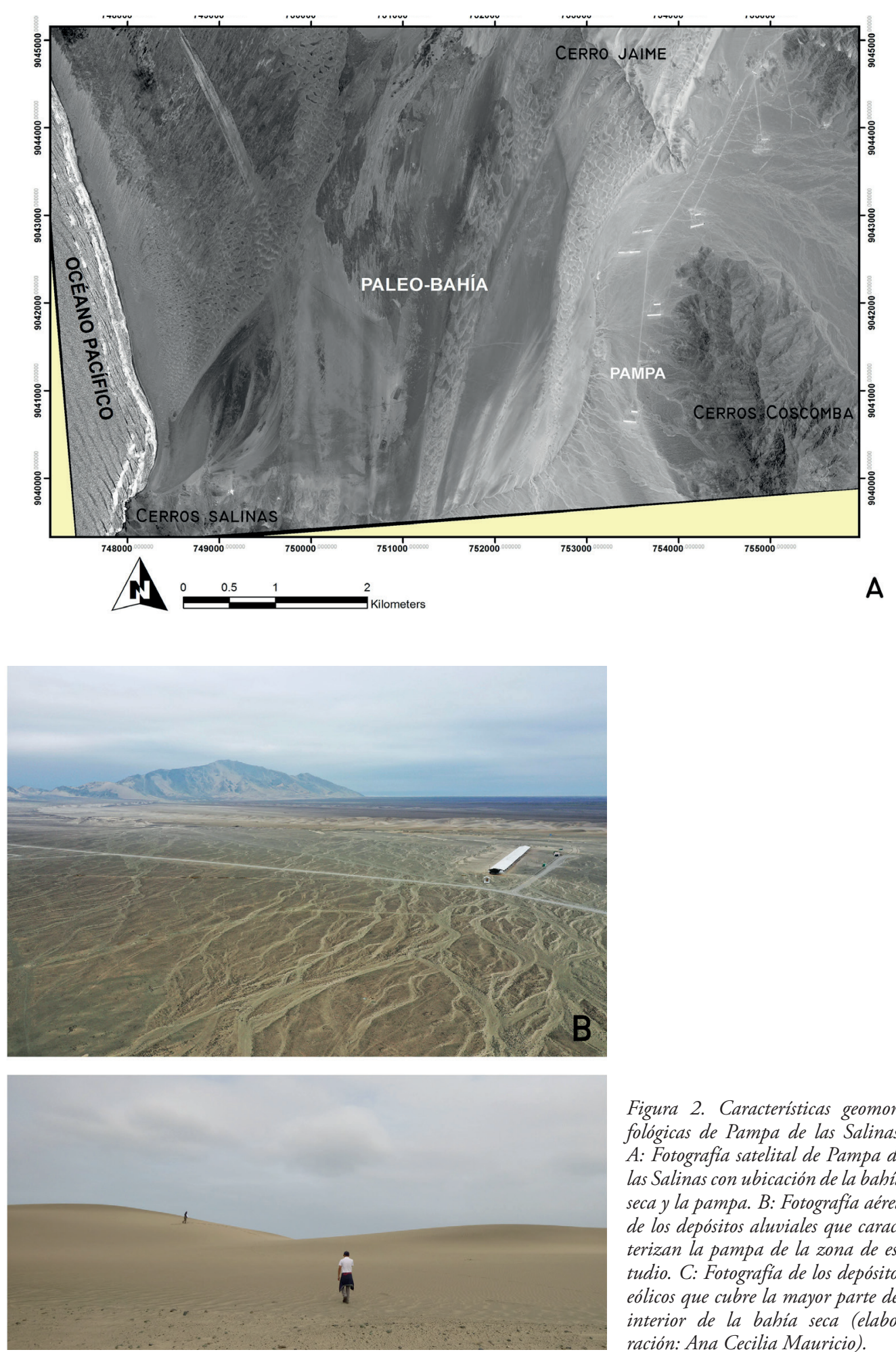

Figura 2. Características geomorfológicas de Pampa de las Salinas. A: Fotografia satelital de Pampa de las Salinas con ubicación de la bahía seca y la pampa. B: Fotografía aérea de los depósitos aluviales que caracterizan la pampa de la zona de estudio. C: Fotografía de los depósitos eólicos que cubre la mayor parte del interior de la bahía seca (elaboración: Ana Cecilia Mauricio). 


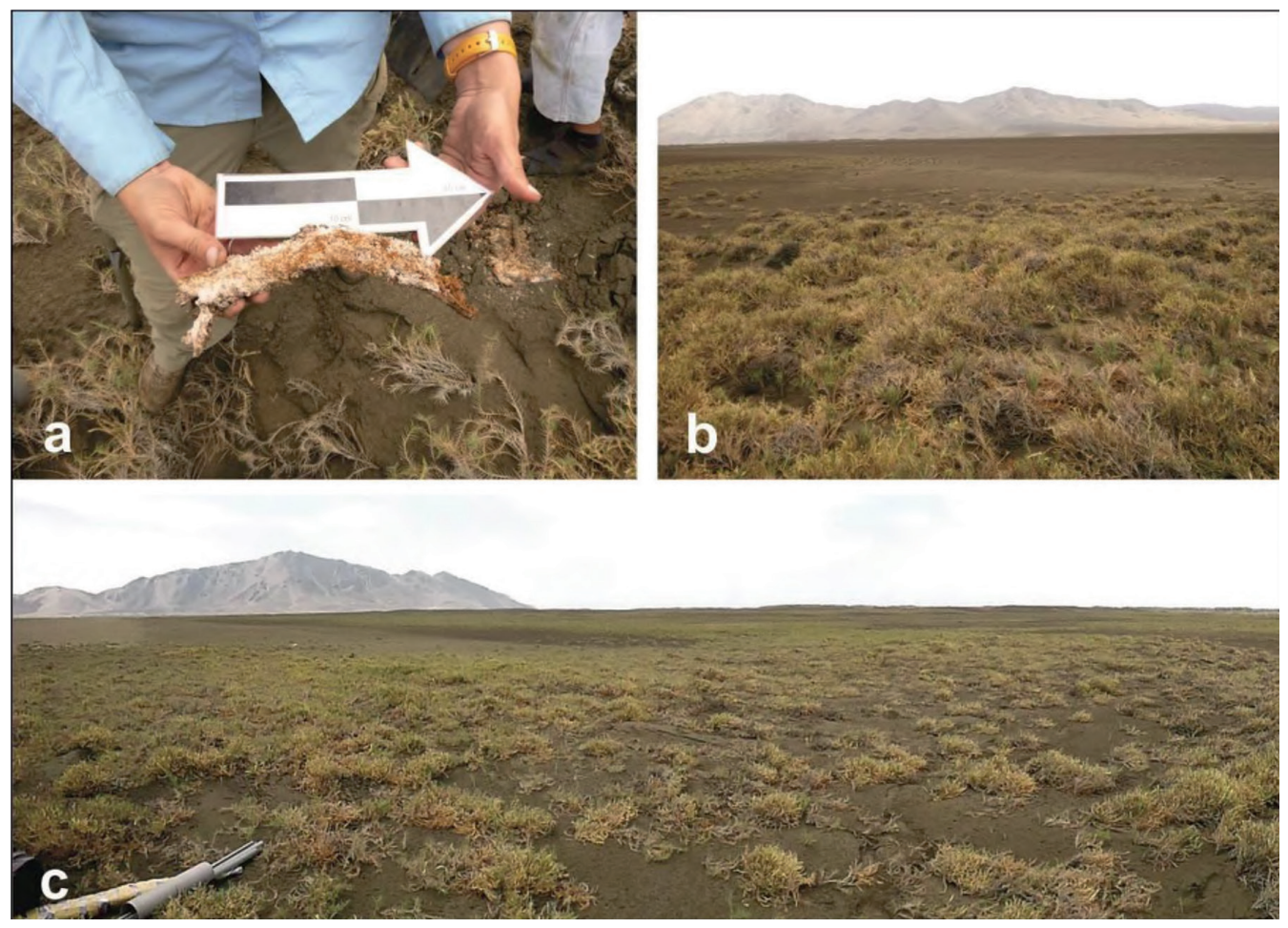

Figura 3. Vegetación de grama salada al interior de la paleobahia. A: Detalle de una raíz cubierta de sal. B y C: Fotografía de la distribución de la vegetación de grama salada en el sector oeste de la bahía seca (elaboración: Ana Cecilia Mauricio).

empresas, una avícola, que tiene numerosas granjas de pollos sobre la llanura, y una agroindustrial, que posee la mayor parte del terreno.

La salinidad es alta en varias secciones de Pampa de las Salinas, principalmente cerca de la línea de playa fósil y dentro de la bahía seca. La superficie del interior de la bahía seca se encuentra cubierta por capas de sal, sobre todo hacia el este y el sur, donde aún se encuentran restos de las instalaciones de una salinera que operaba en esta zona hasta la década de 1970 . Hacia el noroeste, la sección más próxima al mar se caracteriza por la presencia de grama salada (Fig. 3). En la sección suroeste, se encuentran hasta 3 cordones de playa sucesivos, formados por acumulación de cantos rodados, ramas de árboles y material de arrastre, aparentemente procedentes del río Santa (al sur) (Fig. 4). En otras regiones, la formación de estos cordones de playa se asocia a actividad de El Niño (Rollins et al. 1986; Sandweiss 1986).

El viento en Pampa de las Salinas es un elemento determinante en la geomorfología local. Los vientos costeros propios de la costa peruana, tienen una trayectoria similar a la de corriente peruana o de Humboldt, es decir, van de suroeste a noreste y son particularmente intensos en Pampa de las Salinas, entre las 11 de la mañana y las 6 de la tarde. Los depósitos eólicos forman campos dunares que ocupan la bahía seca de sur a norte formando dunas de hasta más de 10 metros de alto. Los depósitos de arena eólica cubren, además, parte de los flancos sur de los cerros Jaime y Salinas. Asimismo, la zona de llanura o pampa contiene capas eólicas de diferente espesor depositadas sobre sedimentos aluviales y entre ellos, los cuales son más profundos en la sección sur de la pampa y cerca de la línea de playa fósil. En la pampa, estos depósitos, junto con los sedimentos aluviales, cubren estructuras arqueológicas, llevando incluso a taparlas por completo. 


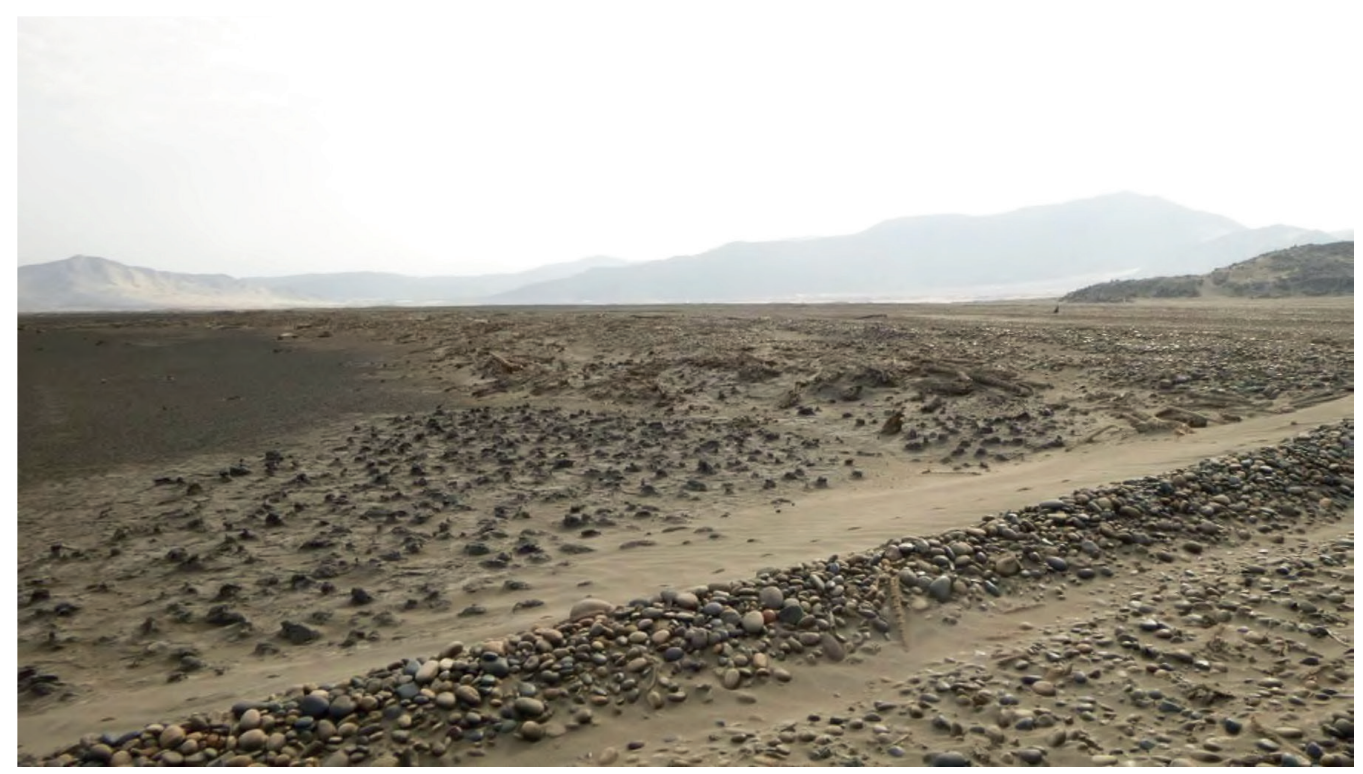

Figura 4. Fotografía de uno de los cordones de playa localizados en el extremo suroeste de la bahía seca. Se pueden observar los cantos rodados y madera de deriva que caracterizan este tipo de depósitos (elaboración: Ana Cecilia Mauricio).

\section{El contexto cultural de Pampa de las Salinas}

A pesar de que el medio ambiente actual de Pampa de las Salinas no resulta muy amigable para la ocupación humana, esta zona alberga más de 20 sitios arqueológicos, la mayoría de los cuales se relaciona al periodo Precerámico Tardío, con una ocupación fechada por radiocarbono entre 6000 y 3000 ańos cal. A.P. (Cárdenas 1999; Mauricio 2015). Como se menciona líneas arriba, casi todos estos sitios fueron registrados en 1976 por Cárdenas y su equipo (Cárdenas 1976); sin embargo, nuestros trabajos desde el año 2012 han registrado cinco sitios adicionales, haciendo un total de 27 sitios y elementos arqueológicos (Fig. 5). El conjunto de sitios de Pampa de las Salinas es diverso en extensión, características arquitectónicas y tipos, casi todos ellos se ubican a lo largo de la pampa.

La mayoría de los asentamientos en Pampa de las Salinas exhiben arquitectura de piedra, siendo Los Morteros, el único sitio que tiene arquitectura de adobe en una de sus fases constructivas. El sitio más extenso es Las Salinas de Chao, el cual tiene una arquitectura de carácter monumental y ceremonial, formado por plataformas adosadas a las faldas de los cerros Cosbomba, así como estructuras cuadrangulares distribuidas en la llanura aluvial, donde también se encuentran dos plazas circulares hundidas y una plaza rectangular (Alva 1986). Le sigue en extensión el sitio Los Pescadores, el cual tiene arquitectura de piedra con grandes espacios cuadrangulares a modo de patios.

Dentro de este conjunto de sitios se encuentran cinco geoglifos, de los cuales, solo cuatro son visibles en la actualidad. Dos de estos geoglifos, Cruz del Sur y Las Marcas, fueron descubiertos y registrados por Cárdenas y su equipo en 1976. Los restantes fueron identificados en nuestras exploraciones del año 2013. Se trata de espacios cuadrangulares de entre 50 a 100 metros de lado, definidos por muros de piedras de una sola hilera. Estos espacios tienen entradas y ambientes interiores, como en el caso de Cruz del Sur. Al interior de estos grandes ambientes cuadrangulares se encuentran acumulaciones circulares de piedras cuyo diámetro puede alcanzar 2.5 metros. Estos geoglifos se encuentran distribuidos en la mitad sur de la pampa, parecen 


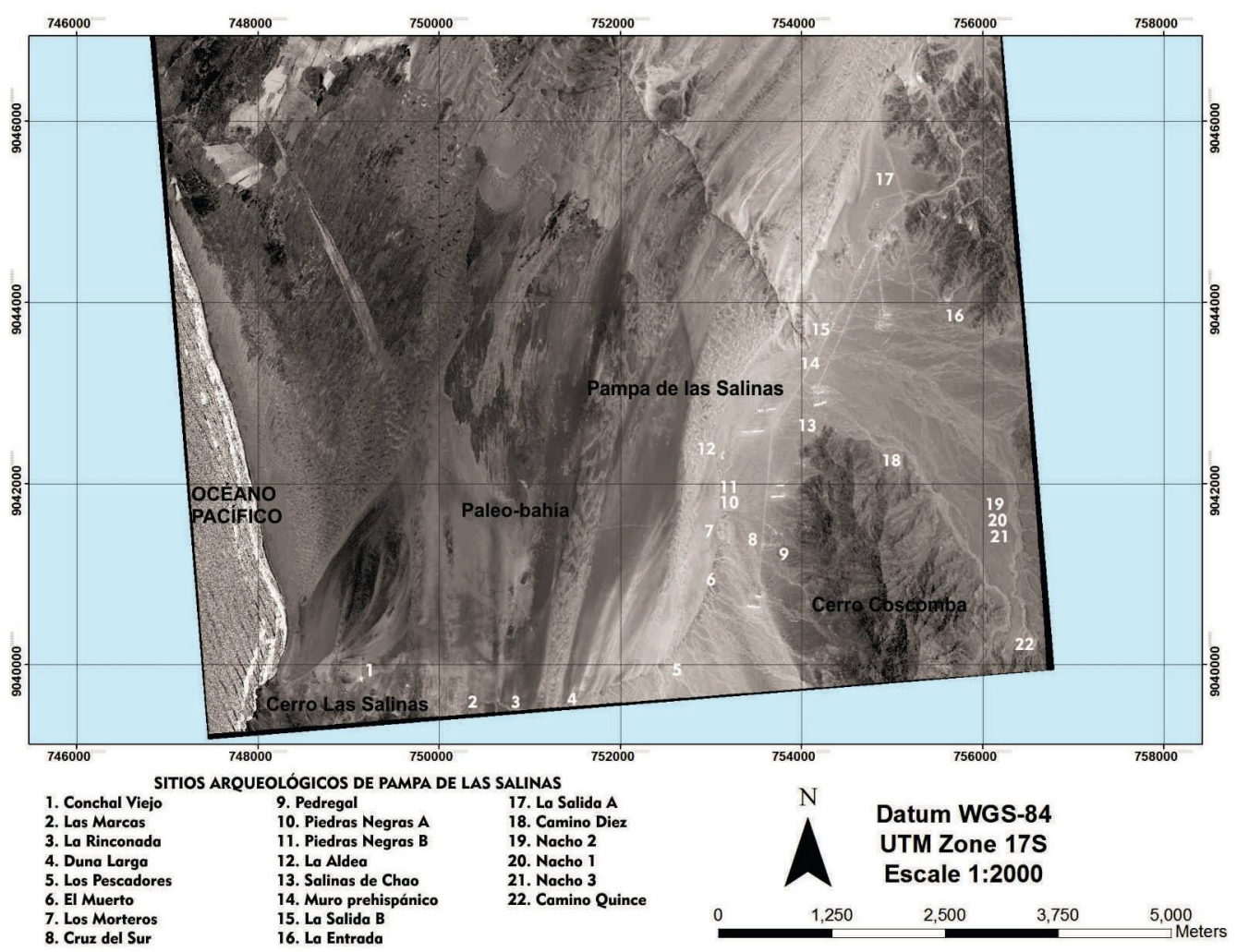

Figura 5. Fotografía satelital de Pampa de las Salinas con la ubicación de los sitios y elementos arqueológicos reportados por el proyecto "Obtención de una cronología para el uso de recursos marinos en el antiguo Perü» (elaboración: Ana Cecilia Mauricio).

representar constelaciones y tienen un carácter ceremonial evidente, en base a su configuración arquitectónica.

Otro tipo de sitios son conchales, tres de ellos se encuentran en el sector noroeste de bahía seca y uno de ellos en el extremo sur de la pampa, muy próximo a la playa actual. En Pampa de las Salinas existen además caminos, muros y conjuntos de paravientos formados por decenas de estructuras de diferente tamaño y forma, los cuales se encuentran en diversas secciones de la pampa.

En base a su cronología, tipos de estructuras y evidencias halladas en los sitios excavados, proponemos que este conjunto de sitios localizados dentro de Pampa de las Salinas corresponde a un Complejo Arqueológico Ceremonial Precerámico, el cual empezó a formarse con la construcción del montículo Los Morteros, hace más de 5700 años cal A.P., y llegó a su punto más alto de popularidad entre, al menos, $4200-4000 \mathrm{cal}$ A.P. y fue abandonado alrededor de $3000 \mathrm{cal}$ A.P.

\section{Los Morteros}

En setiembre de 2012 iniciamos nuestras investigaciones en el sitio Los Morteros y otros sitios y sectores del Complejo Pampa de las Salinas. Las excavaciones en Los Morteros han continuado hasta el año 2021. El sitio Los Morteros se ubica en la parte media de la línea de playa fósil, al borde la misma. Se trata de un montículo de 15 metros de alto por 200 metros de lado. Los Morteros tiene forma escalonada de norte a sur, siendo el perfil sur la zona más elevada (Fig. 6). 


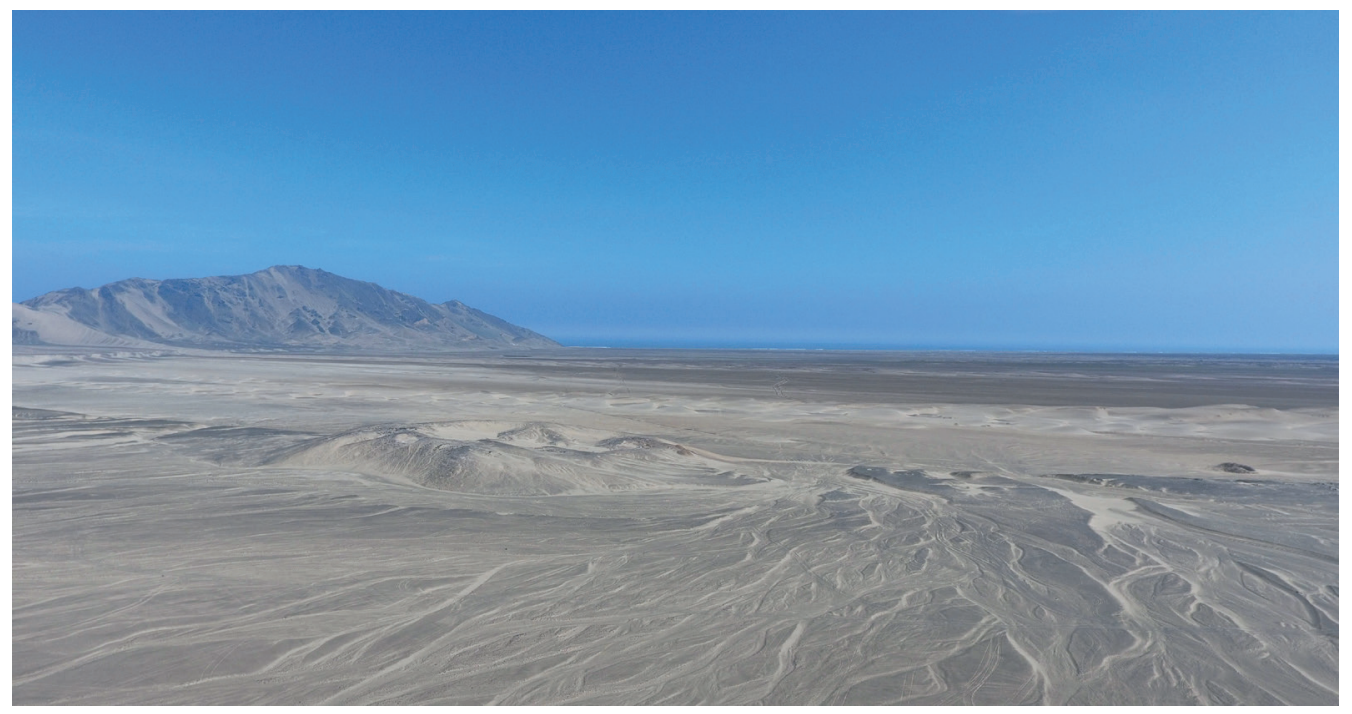

Figura 6. Fotografía aérea del montículo Los Morteros, el fondo (oeste), se observa la bahía seca y el océano Pacifico (fotografia: Ana Cecilia Mauricio).

Nuestras excavaciones extensivas en los sectores sur, norte, este y central de Los Morteros nos han dado hasta la fecha una visión amplia de los complejos procesos de formación y ocupación del sitio. Los datos obtenidos nos permiten proponer, a diferencia de interpretaciones previas (Cárdenas 1976, 1999), que Los Morteros es un montículo artificial, formado por sucesivas ocupaciones precerámicas, las cuales presentan características diferenciadas.

Las diferentes ocupaciones registradas en Los Morteros han sido agrupadas en dos Componentes (I y II). El Componente I está compuesto capas con material cultura que conforman las ocupaciones más antiguas del montículo, aunque estas ocupaciones han sido detectadas y parcialmente registradas en el sector noroeste del montículo, estas no cuentan aún con fechados radiocarbónicos. El Componente II, incluye tres fases de ocupación del sitio. La fase II-1, se trata de una ocupación pre-monumental detectada en el sector central y noroeste del sitio. Esta fase está compuesta por superficies de arcilla, fogones de piedra, restos de fauna marina y micro restos botánicos, los fechados radiocarbónicos obtenidos de estos contextos colocan esta ocupación entre 5700-5400 cal. A.P. Estratigráficamente sobre esta ocupación se encuentra los restos de arquitectura de adobe que corresponden a la fase II-2. Se trata de ambientes rectangulares hechos principalmente de adobes. Las características formales y contextos hallados en el sitio señalan la naturaleza monumental y ceremonial de esta arquitectura. Para detalles sobre esta arquitectura, referimos al lector a trabajos previamente publicados (Mauricio 2014, 2015, 2018, 2019; Mauricio et al. 2021). La fase II-2 ha sido fechada en base a una serie de entierros de niños que formaron parte de una ofrenda de clausura a la arquitectura ceremonial de adobes, en base a 8 fechados, esta fase se encuentra fechada en 5500-5100 cal. A.P. Inmediatamente sobre la arquitectura de adobes, se construye posteriormente una arquitectura de piedra de características igualmente ceremoniales (Mauricio 2014, 2018). Esta superposición se ha registrado en el sector noroeste del montículo; sin embargo, esta arquitectura se ha conservado mejor en la cima del montículo, y existen restos que indican su presencia en diversos sectores del montículo. Esta arquitectura es bastante superficial, tanto en la cima del montículo (sur) como en el sector noreste, fue registrada a pocos centímetros de la superficie actual. Los fechados radiocarbónicos de esta fase se ubican en 5400-5000 cal. A.P. 


\subsection{Cronología}

Los trabajos previos en la zona de Pampa de las Salinas y en el sitio Los Morteros han producido diversos fechados radiocarbónicos, algunos de los cuales vienen de recolección de material malacológico en superficie (Cárdenas 1978/79, 1999; Sandweiss et al. 1983; Perrier et al. 1994). Las excavaciones de Mercedes Cárdenas obtuvieron dos fechados radiocarbónicos para los contextos excavados, los cuales corresponderían a nuestra fase II-3, estos fechados van entre 5500-4800 cal AP. Nuestras excavaciones arqueológicas en diversos sectores de Los Morteros han producido un total de 17 fechados radiocarbónicos, la mayoría de los cuales se basa en material botánico de corta duración, como semillas de algodón. A la fecha, se han fechado por radiocarbono tres ocupaciones en el sitio, registradas como Componente II, estas corresponden a las fases II-1, II-2 y II-3, las cuales van entre 5700-5000 cal A.P. Sin embargo, como se menciona anteriormente, se han identificado ocupaciones preexistentes a aquellas fechadas. Estas ocupaciones han sido registradas como Componente I y se caracterizan por ser capas conteniendo material cultural, como restos orgánicos y superficies de arcilla, las cuales se encuentran estratigráficamente debajo de las fases del componente II.

Los datos obtenidos hasta el momento, han registrado las ocupaciones más tempranas en los sectores central y noroeste del montículo. La ocupación más tardía, fase II-3, asociada a arquitectura ceremonial de piedra, se ha registrado en la cima del montículo (sur), en el sector noroeste y en el sector suroeste; sin embargo, la presencia en superficie de piedras angulares en diversos sectores del montículo, que indican que esta ocupación ocupó toda la superficie del montículo.

\subsection{Estratigrafía}

Nuestras excavaciones en diversos sectores de Los Morteros nos han permitido explorar la estratigrafía del sitio y poder reconstruir los diversos procesos de formación que componen el registro arqueológico de este sitio, el cual se compone de sedimentos naturales, principalmente de origen eólico, y culturales. La estratigrafía del sitio, se ha venido reconstruyendo sobre la base de las excavaciones en diversos sectores del sitio, principalmente los sectores sureste, sur, central y noroeste, como se detalla a continuación. A continuación, resumimos la estratigrafía registrada en cinco unidades de excavación, localizadas en diversos sectores del sitio (Fig. 7).

\subsubsection{Trinchera 1}

La Trinchera 1, fue excavada en el sector sureste del montículo. Como se menciona en el punto 3 , el sector sur del montículo es la parte más elevada. El sector sureste alcanza una altitud aproximada de $20 \mathrm{msnm}$. La Trinchera 1 se excavó como una unidad de $5 \mathrm{~m}$ (norte-sur) x $8 \mathrm{~m}$ (esteoeste), exponiendo aproximadamente 4 metros de estratigrafía de la ladera este del montículo (Fig. 7). Debido a la inestabilidad de los depósitos en este sector, los cuales consistían principalmente en arena eólica, resultó muy difícil poder registrar por completo los perfiles de esta unidad, sin embargo, tanto los perfiles expuestos, como las capas excavadas se complementan para poder entender la naturaleza de los depósitos en este sector del montículo.

\section{Perfil Oeste}

Este perfil fue expuesto de manera escalonada (Fig. 8) para darle estabilidad a los depósitos formados por sedimentos finos y sueltos. Los fuertes vientos de la zona no permitían conservar estos perfiles por mucho tiempo, por lo que solo los primeros dos metros de la estratigrafía de este sector pudieron ser registrados gráficamente.

Estrato 1: pobremente clasificado, arena fina con piedras angulares pequeñas $(<10 \mathrm{~cm})$, fragmentos pequeños de carbón vegetal, conchas marinas y huesos de pescado. 


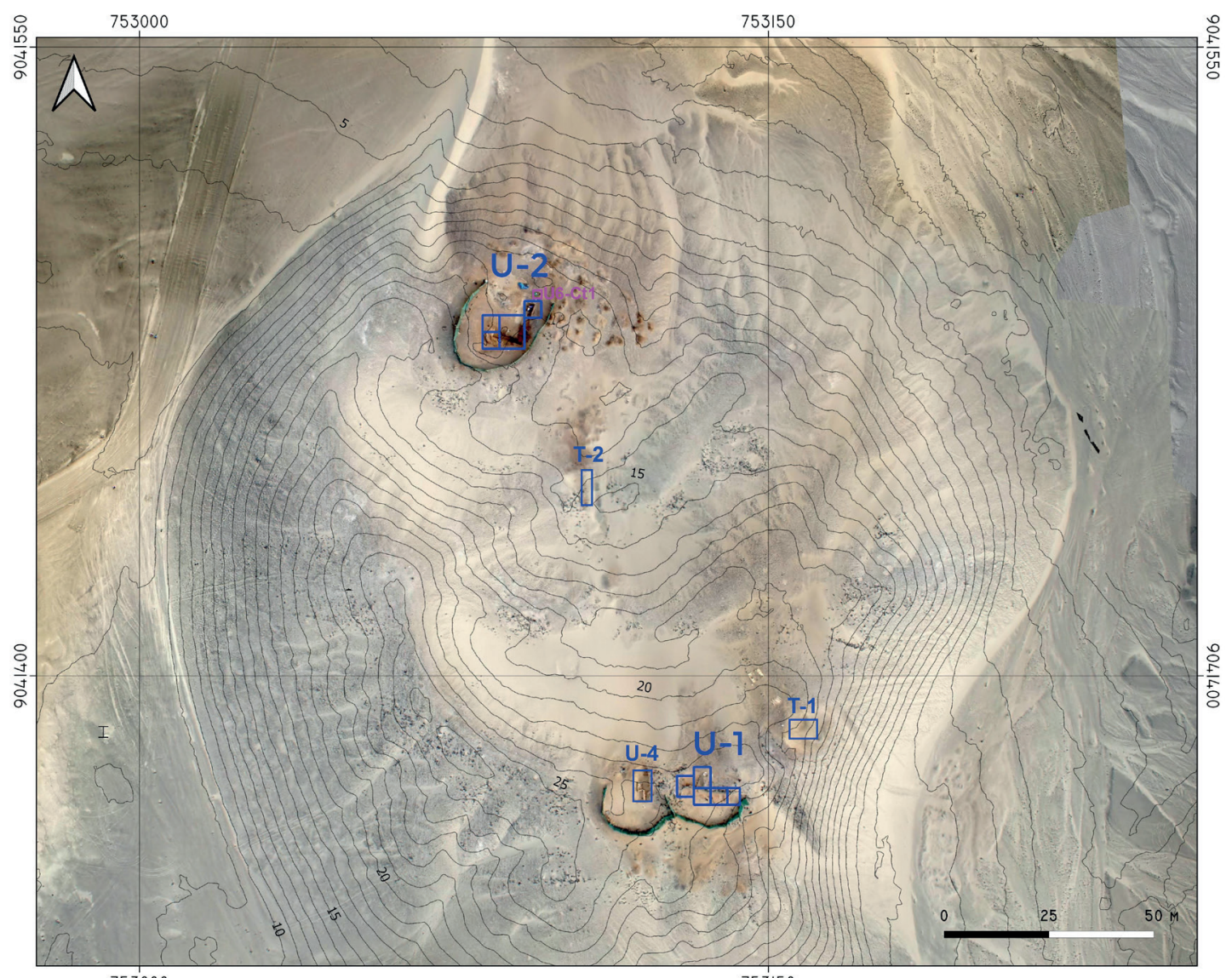

753000

753150

Figura 7. Fotografia aérea del montículo Los Morteros, con curvas de nivel y la ubicación de las unidades de excavación mencionadas en este artículo (elaboración: Ana Cecilia Mauricio).
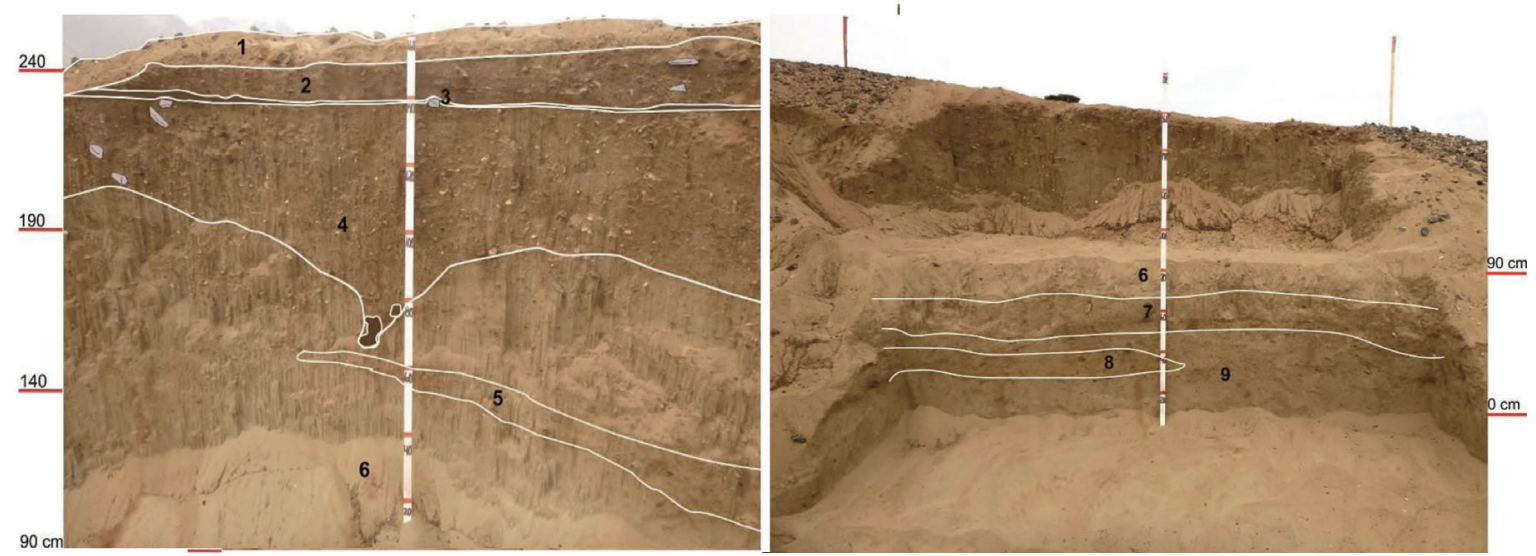

Figura 8. Perfil oeste de la Trinchera 1. Izquierda, mitad sur del perfil; derecha, mitad norte del perfil (elaboración: Ana Cecilia Mauricio). 
Estrato 2: arena fina oscura con abundantes restos orgánicos como huesos de pescado, conchas marinas, fragmentos de carbón vegetal, piedras angulares pequeñas $(<10 \mathrm{~cm})$ y fragmentos de cuerdas y fibras.

Estrato 3: capa fina y compacta conteniendo arena fina marrón muy oscuro, piedras angulares pequeñas $(<3 \mathrm{~cm})$, huesos pequeños de pescado $(<3 \mathrm{~cm})$, carbón vegetal y conchas marinas. Esta capa corresponde a una superficie de actividad.

Estrato 4: pobremente clasificado, arena fina con escasos fragmentos pequeños de carbón vegetal, conchas marinas y terrestres, huesos de pescado y piedras angulares pequeñas $(<5 \mathrm{~cm})$, incluye lentes de arena marrón a rojiza.

Estrato 5: lente de arena fina de coloración marrón oscuro con fragmentos muy pequeños $(<2 \mathrm{~cm})$, de conchas marinas y carbón.

Estrato 6: arena fina de coloración clara con escasos restos orgánicos como fragmentos pequeños $(<1 \mathrm{~cm})$ de carbón y conchas marinas.

Estrato 7: arena fina oscura con muy escasos fragmentos de conchas marinas y carbón. Este estrato continuó en el perfil norte y noreste y corresponde a un depósito denso de conchas de Mesodesma donacium registrado en el lado noreste de esta unidad de excavación. Esta capa corresponde a una superficie de actividad.

Estrato 8: lente de arena fina con muy escasos restos orgánicos como fragmentos pequeños $(<2 \mathrm{~cm})$ de conchas marinas y carbón.

Estrato 9: arena fina de coloración clara con muy escasos restos de carbón y conchas marinas $(<2 \mathrm{~cm})$.

\subsubsection{Unidad 4}

La unidad de excavación 4 se localizó en la parte central de la cima del montículo y tuvo una dimensión total de 9 metros (norte-sur) por 2 metros (este-oeste). El sector donde se ubicó la Unidad 4 tiene una altitud aproximada de $24 \mathrm{msnm}$ (Fig. 7). Las excavaciones en esta unidad alcanzaron una profundidad de aproximada de 3.5 metros.

\section{Perfil Este}

Se trató de un perfil expuesto de manera escalonada durante la excavación de esta unidad, debido a la inestabilidad de los depósitos que componen este sector del montículo. De manera general, la composición estratigráfica de la cima del montículo es muy similar a aquella registrada en la Trinchera 1, ubicada en el lado este de la cima del sitio (Fig. 9). Los depósitos registrados en esta unidad fueron bastante homogéneos, sobre todo en los últimos 3 metros excavados.

Estrato 1: arena fina de coloración oscura con abundantes restos orgánicos como carbón, huesos de pescado, conchas marinas, semillas de algodón y piedras angulares medianas $(<10 \mathrm{~cm})$. Este estrato tenía menor espesor hacia la pendiente norte de la cima del montículo.

Estrato 2: arena fina de coloración clara con escasos restos de pequeños de carbón, huesos de pescado, conchas marinas y piedras angulares pequeñas $(<5 \mathrm{~cm})$.

Estrato 3a, 3b, 3c, 3d: intrusiones alargadas compuestas por arena de coloración oscura las cuales se originan en el estrato 1 y la capa superficial. La forma de estas intrusiones indica la presencia de materiales orgánicos, probablemente postes de madera relacionados a las estructuras de piedra registradas en las primeras capas del área de excavación 1.

Estrato 4: entierro humano marcado por la presencia de bloques de piedra que cubren el cuerpo del entierro. Esta fue la última capa de actividades primarias registradas en esta unidad $(\sim 2$ metros desde la superficie actual).

Estrato 5: arena fina de coloración clara con escasos fragmentos pequeños de carbón y piedras angulares pequeñas $(<3 \mathrm{~cm})$.

Estrato 6: arena fina de coloración oscura con fragmentos pequeños de carbón y huesos de pescado $(<3 \mathrm{~cm})$. 


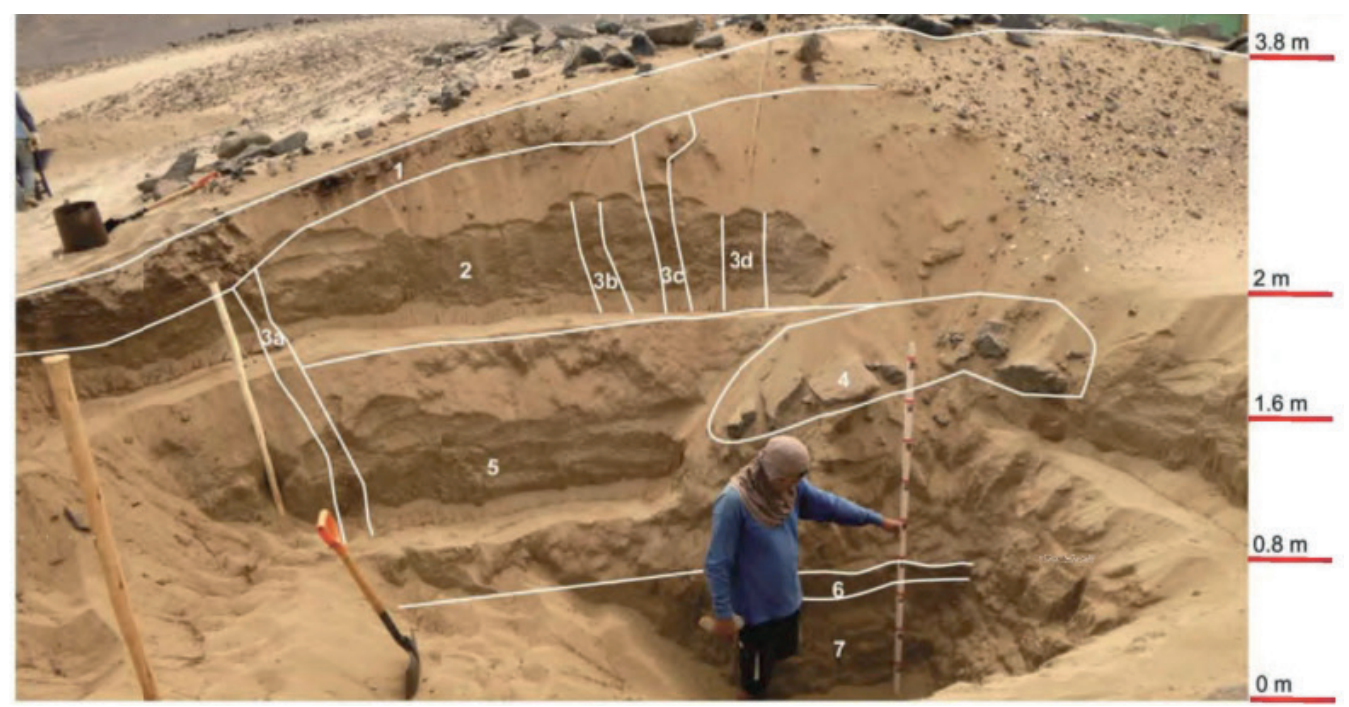

Figura 9. Perfil este de la Unidad 4 (elaboración: Ana Cecilia Mauricio).

Estrato 7: arena fina de coloración marrón con muy escasos fragmentos de carbón y conchas marinas $(<3 \mathrm{~cm})$.

Los últimos 20 a 30 centímetros de este perfil no pudieron ser registrados debido a la inestabilidad de la arena suelta que es la matriz de estos depósitos.

\subsubsection{Trinchera 2}

Esta unidad de excavación se localizó en el sector central del montículo (Fig. 7). Este sector se encuentra a aproximadamente $15 \mathrm{msnm}$. La Trinchera 2 estuvo dividida en 4 sectores. La estratigrafía de esta unidad fue registrada en el Sector 4 el cual tuvo un área de 2 metros (este-oeste) por 10 metros (norte-sur).

Perfil Sur

Este perfil registró 2.1 metros de estratigrafía del sector central del montículo (Fig. 10).

Estrato 1: arena fina de coloración clara, sin elementos orgánicos.

Estrato 2: arena fina de coloración clara con piedras angulares pequeñas $(<10 \mathrm{~cm})$, pequeños fragmentos de huesos de pescado, conchas marinas, carbón y semillas.

Estrato 3: arena fina de coloración oscura con pedazos pequeños de carbón $(<10 \mathrm{~cm})$.

Estrato 4: arena fina de coloración clara con rocas angulares muy pequeñas $(<3 \mathrm{~cm})$ y pequeños fragmentos de carbón.

Estrato 5: arena muy fina de coloración marrón oscura, pequeños fragmentos de carbón, conchas marinas y piedras angulares muy pequeñas $(<3 \mathrm{~cm})$. Este estrato marca una superficie de actividad similar a aquellas registradas en el Trinchera 1 y el Área 4.

Estrato 6: arena fina de coloración clara, escasos restos orgánicos como fragmentos muy pequeños de carbón, conchas marinas y piedras angulares $(<3 \mathrm{~cm})$.

Estrato 7: (lado oeste del perfil), depósito de conchas de Argopecten y pedazos de carbón.

Estrato 8: arena fina de coloración marrón con escasos restos orgánicos muy pequeños como carbón, conchas marinas, huesos de pescado y piedras angulares muy pequeñas $(<3 \mathrm{~cm})$.

Estrato 9: arena fina de coloración clara con rocas angulares muy pequeñas $(<3 \mathrm{~cm})$ y restos de carbón y conchas marinas. 

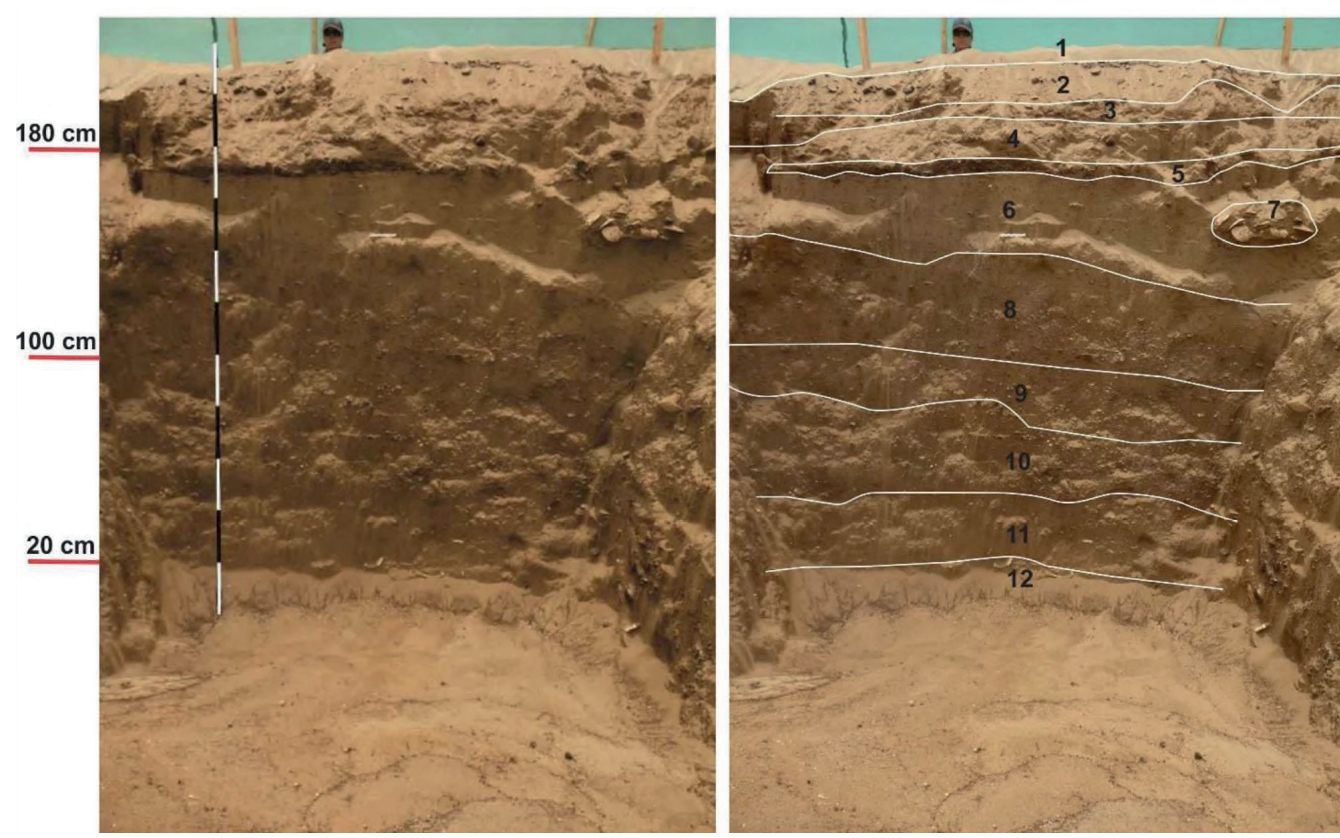

Figura 10. Perfil sur de la Trinchera 2 (elaboración: Ana Cecilia Mauricio).

Estrato 10: arena fina de coloración oscura con escasos restos orgánicos muy pequeños $(<2 \mathrm{~cm})$ de carbón y conchas marinas.

Estrato 11: arena fina de coloración clara con escasos y muy pequeños restos de conchas marinas $(<2 \mathrm{~cm})$.

Estrato 12: arena fina de coloración clara con piedras angulares medianas $(-10 \mathrm{~cm})$, carbón y conchas de Argopecten, se trató de los restos de un fogón.

\subsubsection{Unidad 6-Cateo 1}

La Unidad 6 se ubicó en el sector noroeste del montículo, inmediatamente al norte de la Unidad 2 y tuvo una extensión de 6 metros (este-oeste) por 14 metros (norte-sur). Este sector del montículo se encuentra a aproximadamente $12 \mathrm{msnm}$ (Fig. 7). El Cateo 1 tuvo un área de 1.5 metros por 1.5 metros y se ubicó en la esquina sureste de esta unidad, inmediatamente al norte de la esquina noreste del ambiente de adobes registrada en la Unidad 2. Las excavaciones de este cateo se iniciaron a partir de la superficie de la capa 6 de la Unidad.

\section{Perfil Este}

Este perfil registra aproximadamente 3 metros de estratigrafía en el sector noroeste del montículo e incluye ocupaciones monumentales y pre monumentales (Fig. 11).

Estrato 1: superficie actual del montículo, arena fina con abundantes restos orgánicos como huesos de pescado, conchas marinas, carbón y piedras angulares pequeñas $(<10 \mathrm{~cm})$.

Estrato 2: arena fina de coloración clara con restos orgánicos pequeños $(<10 \mathrm{~cm})$ como como huesos de pescado, conchas marinas, carbón.

Estrato 3: arena fina de coloración media con restos orgánicos pequeños $(<10 \mathrm{~cm})$ como como huesos de pescado, conchas marinas, carbón y piedras angulares.

Estrato 4: arena fina de coloración oscura con abundantes restos orgánicos muy pequeños $(<5 \mathrm{~cm})$ como huesos de pescado, conchas marinas, carbón y piedras angulares. 


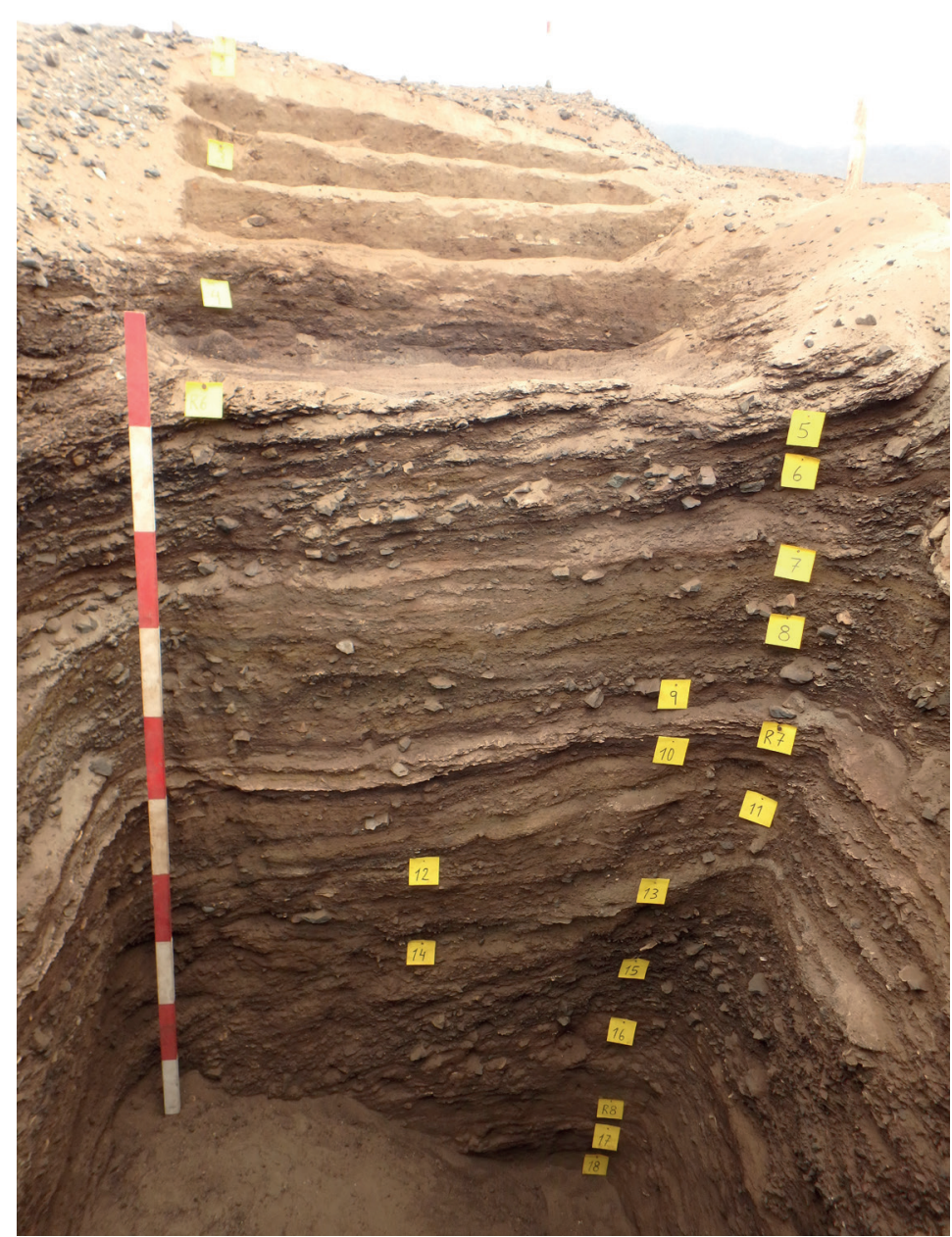

Figura 11. Perfil este del Cateo 1, Unidad 6 (elaboración: Ana Cecilia Mauricio).

Estrato 5: arena fina de coloración muy oscura con huellas de quema y abundantes restos orgánicos como huesos de pescado, huesos de lobo marino, conchas marinas, carbón, ceniza y piedras angulares pequeñas $(<10 \mathrm{~cm})$.

Rasgo 6: lente con ceniza dentro del estrato 5 conteniendo fragmentos pequeños de carbón y conchas marinas $(<5 \mathrm{~cm})$.

Estrato 6: arena media de coloración oscura con abundantes piedras angulares pequeñas $(<10 \mathrm{~cm})$ y restos orgánicos como carbón, ceniza y fragmentos de conchas marinas.

Estrato 7: arena fina de coloración oscura, conteniendo restos pequeños $(<5 \mathrm{~cm})$ de carbón, conchas marinas y piedras angulares.

Estrato 8: arena muy fina de coloración verdosa, conteniendo restos pequeños $(<5 \mathrm{~cm})$ de carbón, conchas marinas y piedras angulares.

Estrato 9: arena media conteniendo abundantes piedras angulares pequeñas $(<5 \mathrm{~cm})$, así como fragmentos pequeños de carbón.

Rasgo 7: superficie arcillosa. Se trata del piso arquitectónico del ambiente de adobes registrado en el Área 2, el cual se puede observar en el perfil sur de este cateo.

Estrato 10: arena fina de coloración marrón oscuro con restos pequeños $(<5 \mathrm{~cm})$ de carbón y conchas marinas. 
Estrato 11: arena fina suelta de coloración marrón muy oscuro, contenía abundantes restos orgánicos descompuestos.

Estrato 12: superficie semi compacta arcillosa, con restos de ceniza, la superficie presentó posibles hoyos de poste de 5 centímetros de diámetro.

Estrato 13: arena arcillosa de coloración marrón amarillento oscuro.

Estrato 14: arena fina suelta de coloración marrón oscuro, contenía abundantes restos orgánicos descompuestos.

Estrato 15: arena fina de coloración marrón muy oscuro con piedras angulares de menos de $10 \mathrm{~cm}$.

Estrato 16: arena fina suelta de coloración marrón oscuro con escasas piedras angulares de menos de $10 \mathrm{~cm}$ y escasos restos orgánicos.

Rasgo 8: superficie arcillosa, probable superficie de uso.

Estrato 7: arena fina de coloración marrón con escasos restos orgánicos.

Estrato 18: arena fina de coloración marrón claro con escasos restos orgánicos.

\section{Los procesos de formación de Los Morteros}

Los Morteros fue inicialmente interpretado como montículo de origen natural (Cárdenas 1976); sin embargo, excavaciones arqueológicas en diversos sectores han permitido reconstruir los procesos de formación de este montículo, los mismos que resaltan origen antropológico y la intervención de procesos geológicos en la configuración del mismo.

Por un lado, las excavaciones en la Trinchera 1 y la Unidad 4, localizadas en el sector sur del montículo, la parte más elevada del mismo, muestran la naturaleza eólica de los depósitos de arena que caracterizan, al menos los primeros 4 metros de la estratigrafía en este sector. La cima del montículo (sur) se encuentra a aproximadamente $25 \mathrm{msnm}$, la base del montículo en el sector suroeste se encuentra a aproximadamente $10 \mathrm{msnm}$, lo que indica una altura máxima del montículo 15 metros en el lado sur, de los cuales, al menos los últimos 4 metros acumulados son arena eólica. De acuerdo a las unidades excavadas en el sector sur, los contextos culturales primarios se registraron en los niveles más superficiales de la Unidad 1 y 4 , dentro del primer metro (1 metro) debajo de la superficie actual. En este sector los fechados radiocarbónicos son 5400-5000 cal AP (Tabla 1).

Por otro lado, las excavaciones en la Trinchera 2, localizada en el sector central del montículo, registraron una estratigrafía de al menos 2 metros de profundidad, compuesta por depósitos culturales y eólicos, sin arquitectura mayor. El sector central del montículo se encuentra a aproximadamente $14 \mathrm{msnm}$, de los cuales 2 metros son depósitos culturales, los más profundos de ellos arrojaron un fechado radiocarbónicas de 5700-5400 cal AP. La base del montículo alrededor del en el sector central se encuentra entre 3 y $5 \mathrm{msnm}$, lo que indica una densidad de depósitos culturales en este sector de entre 10 y 12 metros, de los cuales se han registrado los primeros 2 metros.

En el sector noroeste las excavaciones en la Unidad 2 muestran una estratigrafía cultural compuesta por arquitectura de piedra $(20 \mathrm{~cm}$ a 1 metro de profundidad $)$ y de adobe $(1 \mathrm{a} 3$ metros de profundidad), es decir, en los primeros 3 metros de la estratigrafía de este sector. Las excavaciones en el Cateo 1 de la Unidad 6, indican la presencia de depósitos culturales y naturales, sin arquitectura mayor, hasta al menos 2 metros por debajo de la arquitectura de adobes. Este sector del montículo se encuentra a aproximadamente $13 \mathrm{msnm}$ y la base del montículo entre 3 y 5 msnm, lo cual le da a este sector una densidad de depósitos culturales de entre 8 y 10 metros, de los cuales se ha registrado los primeros 5 metros. En este sector los fechados radiocarbónicos obtenidos están entre 5600 y $5100 \mathrm{cal} \mathrm{AP.}$

Sobre la base de los fechados obtenidos, la arquitectura registrada y la altura de los depósitos naturales y culturales podemos ensayar una primera interpretación del proceso de formación del 
FECHADOS RADIOCARBÓNICOS DEL SITIO LOS MORTEROS

\begin{tabular}{|c|c|c|c|c|c|c|c|}
\hline Sitio & Código de la muestra & $\begin{array}{c}\text { Fecha } \\
\text { C14 }\end{array}$ & $\begin{array}{l}\text { Incerti- } \\
\text { dumbre }\end{array}$ & $2 \sigma \mathrm{cal} \mathrm{AP}$ & $\begin{array}{l}\text { Código de } \\
\text { laboratorio }\end{array}$ & $\begin{array}{c}\text { Código del } \\
\text { proyecto }\end{array}$ & Material \\
\hline Los Morteros & Morteros_PRAET_01 & 4629 & 63 & $5477-4990$ & AA104438 & A1-S1-C1-OG17 & Semilla quemada \\
\hline Los Morteros & Morteros_PRAET_02 & 4686 & 33 & $5475-5304$ & D-AMS 033203 & T3-C2-OG78-R19 & Carbón \\
\hline Los Morteros & Morteros_PRAET_03 & 4548 & 31 & $5312-4990$ & D-AMS 033202 & A5-C4-MU12 & Estera \\
\hline Los Morteros & Morteros_PRAET_04 & 4583 & 54 & $5446-4977$ & D-AMS 033197 & A2-S3-C5-T201-OG04 & Estera \\
\hline Los Morteros & Morteros_PRAET_05 & 4935 & 45 & $5746-5482$ & D-AMS 033204 & A2-S3-T201-OH01 & Diente humano \\
\hline Los Morteros & Morteros_PRAET_06 & 4445 & 43 & $5280-4857$ & D-AMS 033205 & A2-S3-T202-OH01 & Diente humano \\
\hline Los Morteros & Morteros_PRAET_07 & 4592 & 33 & $5439-5048$ & D-AMS 033199 & A2-S3-C5-T202-TX04 & Textil quemado \\
\hline Los Morteros & Morteros_PRAET_08 & 4539 & 33 & $5309-4982$ & D-AMS 033198 & A2-S3-C5-T202-TX02 & Textil quemado \\
\hline Los Morteros & Morteros_PRAET_09 & 4409 & 32 & $5213-4846$ & D-AMS 033201 & A2-S3-C7-T203-OG01 & Mate \\
\hline Los Morteros & Morteros_PRAET_10 & 4808 & 45 & $5594-5327$ & D-AMS 033200 & A2-S3-C7-T203-OG001 & Estera \\
\hline Los Morteros & Morteros_PRAET_11 & 5037 & 33 & $5895-5603$ & D-AMS 033206 & A2-S3-T203-OH01 & Diente humano \\
\hline Los Morteros & Morteros_PRAET_12 & 4641 & 53 & $5474-5051$ & AA104439 & A2-S3-3-C8-OG34 & Caña \\
\hline Los Morteros & Morteros_PRAET_13 & 4880 & 30 & $5654-5476$ & Beta -467140 & A6-CT1-C10-MU89 & Carbón \\
\hline Los Morteros & Morteros_PRAET_14 & 4680 & 30 & $5469-5308$ & Beta - 467141 & A6-CT1-C11-MU90 & Carbón \\
\hline Los Morteros & Morteros_PRAET_15 & 4700 & 30 & $5547-5310$ & Beta -467142 & A6-CT1-C14-MU92 & Carbón \\
\hline Los Morteros & Morteros_PRAET_16 & 4660 & 30 & $5470-5289$ & Beta -467143 & A6-CT1-C15-MU93 & Carbón \\
\hline Los Morteros & Morteros_PRAET_17 & 4916 & 48 & $5736-5477$ & AA104440 & T2-S4-C6-R4-OG13 & Carbón \\
\hline Los Morteros & Morteros_PUCP_26 & 4656 & 60 & $5573-5051$ & PUCP-26 & PUCP-26 & Carbón \\
\hline Los Morteros & Morteros_PUCP_27 & 4560 & 60 & $5444-4889$ & PUCP-27 & PUCP-27 & Carbón \\
\hline
\end{tabular}

Tabla 1. Fechados radiocarbónicos del sitio Los Morteros, calibrados a $2 \sigma$ (fechas calibradas usando Oxcal 4.4.2/ ShCal20 atmospheric and Marine.20. Elaboración: Ana Cecilia Mauricio).

montículo. La formación de Los Morteros se inició en el sector norte y central del montículo, probablemente con un pequeño montículo que alcanzó una altura de entre 3 a 8 metros, del cual se tiene evidencia en los sectores noroeste y central (Fig. 12A y 12C). Por su posición estratigráfica, esta ocupación inicial parece empezar antes de $6000 \mathrm{cal} \mathrm{AP,} \mathrm{sin} \mathrm{embargo,} \mathrm{estos} \mathrm{depósitos} \mathrm{aún}$ deben ser fechados. Estos depósitos tempranos no presentan arquitectura mayor y han sido denominados Componente I del sitio.

Sobre estos depósitos del Componente I se encuentran los depósitos de tres fases de ocupación, los cuales han sido denominados Componente II. La primera fase de este componente, fase II-1, consiste en depósitos orgánicos con restos de fogones y superficies de arcilla fechados en 5700$5400 \mathrm{cal} \mathrm{AP} \mathrm{(Fig.} \mathrm{12A).} \mathrm{Se} \mathrm{superpone} \mathrm{la} \mathrm{fase} \mathrm{II-2,} \mathrm{que} \mathrm{corresponde} \mathrm{a} \mathrm{la} \mathrm{construcción} \mathrm{de} \mathrm{arquitec-}$ tura monumental de adobes, la cual ha sido registrada en el sector noroeste del montículo y tiene fechados entre 5500-5100 cal. AP (Fig. 12A). La fase más tardía de construcción del montículo es la fase II-3, la cual corresponde a la construcción de arquitectura monumental de piedra fechada en 5400-5000 cal AP (Fig. 12A).

Las excavaciones en diversos sectores del sitio indican que Los Morteros inició como un montículo de poca elevación, Componente I, de entre 3 y 8 metros de altura. Este componente inicial de empezó a acumular arena eólica de manera constante, en sus lados sur, este y oeste, lo cual formó el sustrato de las ocupaciones posteriores. Sobre estos depósitos culturales y eólicos se construyen las fases del Componente II, primero como ocupaciones menores de la fase II-1 y luego la arquitectura de adobes de la fase II-2. Estas fases de ocupación y construcción continuaron acumulando arena eólica, — probablemente con más rapidez debido a la construcción de 


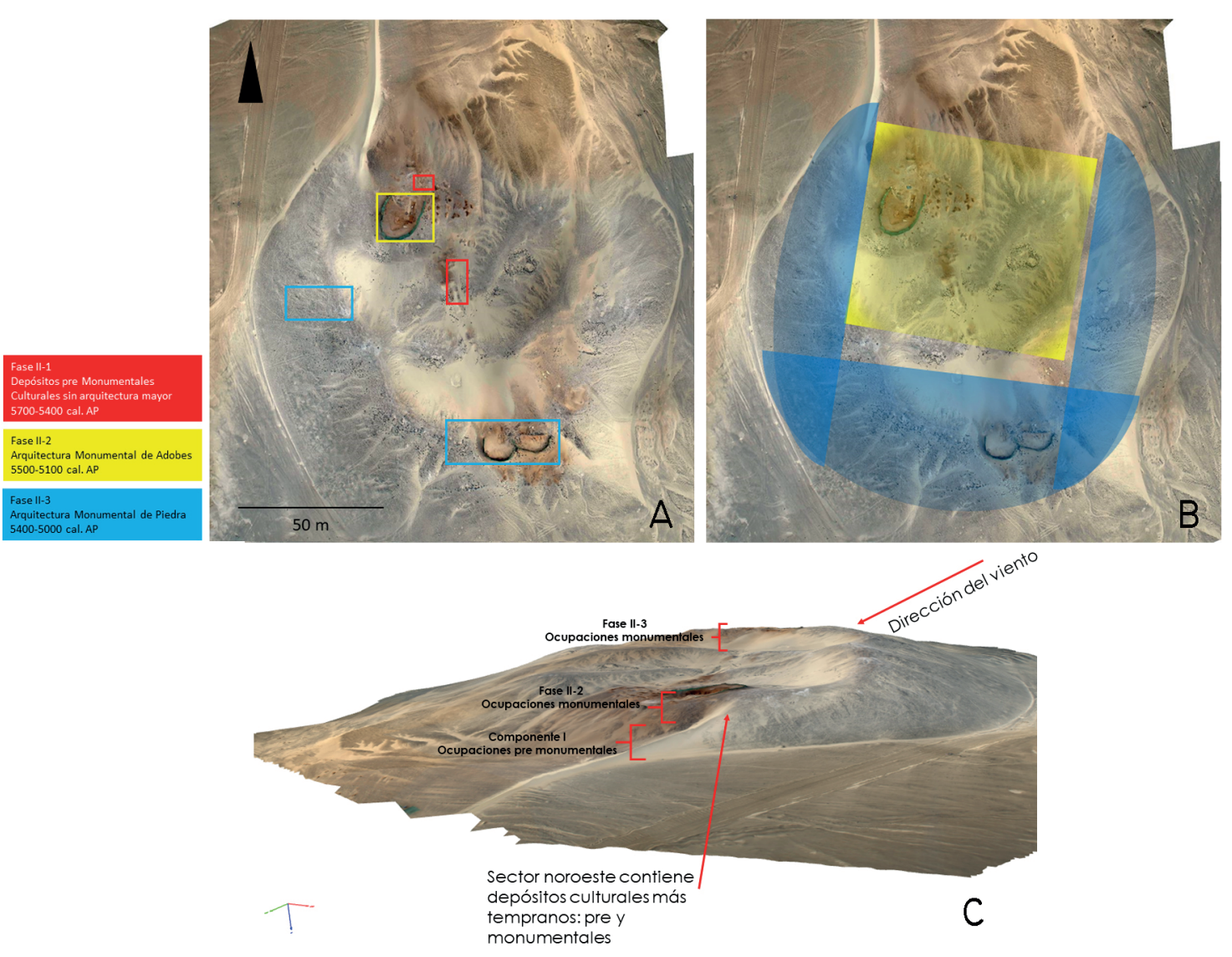

Figura 12. Procesos de formación del montículo Los Morteros. A: Localización de las distintas fases del Componente II en el monticulo. B: Ubicación de los depósitos eólicos en los lados sur, este y oeste del montículo. C: Fotografía en 3D, con la localización de los depósitos del Componente I y las fases del Componente II (elaboración: Ana Cecilia Mauricio).

estructuras de adobe-, de la misma manera en la que se produce la formación de dunas barjanes, con una pendiente de inclinación suave a barlovento (lado sur) y una pendiente más inclinada en a sotavento (lado norte) (Fig. 12B y 12C) (Bird 2008). El componente inicial del montículo, Componente I, sirvió de obstáculo para «atrapar» arena transportada por los fuertes vientos costeros que predominan en la zona durante la mayor parte del día, los cuales circulan de suroeste a noreste. Estos depósitos eólicos se acumularon en los lados del montículo, formando una «u» o herradura en sentido a la dirección del viento (Fig. 12B), forma característica de las dunas barjanes (Waters 1992; Bird 2008).

Las fechas radiocarbónicas disponibles para todas las ocupaciones registradas indican una continua ocupación del montículo y un rápido y constante proceso de acarreo eólico, considerando la densidad de los depósitos de arena eólica en el sector norte y la proximidad de la cronología radiocarbónica entre los sectores sur y norte.

El montículo ha dejado de acumular arena eólica de manera significativa en el sector sur (la parte más alta del montículo) debido a la altura alcanzada; sin embargo, la acumulación ha continuado en la ladera oeste y la pendiente central. La ladera este sufrió alteración por una escorrentía que pasó por esta zona y erosionó este lado del montículo, descubriendo, además, los depósitos de arena que predominan en este sector. Las dunas barjanes pueden medir hasta 30 metros de alto, 
la acumulación de arena se da más en los costados que en el lado a barlovento, por lo que pueden llegar una forma alargada y pueden «moverse» en dirección al viento (Waters 1992; Bird 2008).

\section{Los Morteros y el Complejo Ceremonial de Pampa de las Salinas}

El sitio Los Morteros es el sitio mejor fechado y, hasta la fecha, el que cuenta con los fechados más tempranos del Complejo Pampa de las Salinas, con una ocupación que va entre 5700-5000 cal A.P., sobre la base de 17 fechados radiocarbónicos recientes, a los que se le pueden sumar dos fechados previos obtenidos por Cárdenas y su equipo, los cuales corresponden con los nuestros (Cárdenas 1999; Tabla 1). Además, las excavaciones en Los Morteros han permitido registrar un complejo proceso de formación y construcción del montículo, lo cual incluye ocupaciones monumentales y pre monumentales durante el Periodo Precerámico Tardío y el Precerámico Medio.

El sitio Los Morteros presenta arquitectura monumental en dos fases del Componente II, las cuales fechan entre 5500-5000 cal A.P. (arquitectura de adobes y de piedra), constituyéndose en uno de los ejemplos más tempranos de arquitectura monumental en los Andes y en el continente americano (Mauricio et al. 2021). La arquitectura monumental de Los Morteros, tanto de adobes como de piedra, se asocia a la construcción de espacios de carácter ceremonial y comunitario. Se han registrado, además, evidencias de ofrendas y actividades relacionadas a la clausura de la arquitectura monumental de adobes, así como eventos funerarios, relacionados a las últimas fases de ocupación del sitio, incluyendo la arquitectura de piedra (Mauricio 2015, Mauricio et al. 2021).

Como se menciona líneas arriba, el sitio Los Morteros se encuentra rodeado de más de 20 sitios y estructuras arqueológicas, en su mayoría precerámicos. En base a los antecedentes de la zona (Cárdenas 1976, 1999) y, principalmente, en base a nuestras recientes investigaciones (Mauricio 2014, 2015, 2018) llevadas a cabo en seis de estos sitios, proponemos que Pampa de las Salinas fue un importante Complejo Ceremonial, comunal, entre al menos, 4200-3000 cal A.P. Este Complejo Ceremonial habría tenido como uno de los espacios principales al sitio Las Salinas de Chao, el más extenso del Complejo, conformado por tres plazas y múltiples terrazas y patios construidos sobre la ladera oeste de los Cerros Coscomba y en la llanura colindante (Alva 1986). El Complejo Ceremonial Pampa de las Salinas, estuvo compuesto por sitios como Piedras Negras, Los Pescadores y las áreas de geoglifos reportadas en la zona. De acuerdo a los fechados radiocarbónicos disponibles (Tabla 1), estos asentamientos fueron contemporáneos, al menos durante el periodo de 4200-3000 cal A.P. Aunque los geoglifos no han sido excavados todavía, proponemos que estos serían contemporáneos con la mayoría de sitios de carácter ceremonial comunal que existen en el complejo, los cuales coindicen en su cronología. Pampa de las Salinas registra reocupaciones asociadas a poblaciones con cerámica en sitios como Las Salinas de Chao; sin embargo, hasta la fecha no se ha reportado que estas ocupaciones hayan construido edificaciones propias en la zona. Estas ocupaciones tardías parecen haber reusado la arquitectura anterior para construir estructuras sin mortero sobre las anteriores, este es el caso de sitios como Las Salinas de Chao y Piedras Negras.

La transformación de Pampa de las Salinas en un gran Complejo Ceremonial comienza con la formación del montículo Los Morteros, el cual se convierte en un espacio ritual, un hito central en la formación de un paisaje ceremonial, alrededor del cual se edificó un complejo ceremonial de grandes dimensiones, donde primó la construcción de espacios ceremoniales de congregación.

Existe aún una brecha de casi 800 años entre la última fase constructiva de Los Morteros (arquitectura de piedra de la fase II-3) y las ocupaciones más tempranas fechadas en otros asentamientos monumentales, como Las Salinas de Chao. Esta brecha cronológica podría indicar un momento de abandono de la zona entre 5000 y 4200 A.P., o, como lo indican nuestras excavaciones y lo sugiere la cronología radiocarbónica del Complejo, existen ocupaciones más tempranas en los sitios con arquitectura monumental. Estas posibles ocupaciones pre monumentales han sido sugeridas por investigaciones previas de Cárdenas y su equipo (Cárdenas 1976; Alva 1986). 


\section{Conclusiones}

Este artículo presenta un primer acercamiento a los complejos procesos de formación del sitio Los Morteros; sin embargo, es necesario continuar con las investigaciones, es importante continuar el registro de las ocupaciones pre monumentales y sobre todo continuar las excavaciones en el sector sur del montículo. Es necesario entender, de manera más detallada, la naturaleza de los depósitos pre-monumentales, y el aporte antropogénico y/o geológico en la formación de estos depósitos. Es decir, es importante reconocer el origen del montículo, ¿se trata de un montículo que inicia su formación como un pequeño montículo de carácter artificial, formado principalmente por depósitos antropogénicos, el cual, por su ubicación, comienza a acumular arena eólica constantemente? ¿Esta dinámica — actividad antropogénica más acumulación eólica- habría dado como resultado el montículo que observamos? Otra posible explicación de la formación inicial de Los Morteros podría estar relacionada a la existencia de un elemento natural (v.g., un afloramiento rocoso) que actuó como barrera para «atrapar» depósitos eólicos. Finalmente, es factible que Los Morteros haya iniciado su formación por un proceso artificial cultural que "construyó» un montículo por la acumulación de sedimentos de manera artificial e intencional. Por ahora, esta última posibilidad es la menos factible, en razón a la naturaleza de los depósitos registrados en todas las unidades excavadas.

Nuestra aproximación geoarqueológica y paleoambiental nos ha permitido, hasta ahora, tener una perspectiva más comprehensiva de este tema, sin embargo, es necesario continuar con el registro de la estratigrafía de los diversos sectores del montículo, así como con su datación radiocarbónica.

El entendimiento de la formación del registro arqueológico de Los Morteros nos permite acercarnos al entendimiento de la cronología y los procesos involucrados en el desarrollo de la complejidad social, reflejada en el desarrollo de las primeras expresiones monumentales y rituales de esta zona. En este sentido, la configuración del registro arqueológico del sitio Los Morteros ofrece una secuencia bastante completa, que incluye etapas previas y posteriores a la construcción de estructuras monumentales, lo cual es bastante inusual de encontrar en asentamientos de similar cronología y características arquitectónicas. La riqueza de la secuencia estratigráfica de los Los Morteros permite además, el estudio de estas transformaciones sociales desde una perspectiva diacrónica y sincrónica. Asimismo, el contexto único de Los Morteros y el enfoque de nuestras investigaciones nos permite tener un conocimiento más profundo de sus dinámicas sociales, ya que se privilegia el estudio de este sitio dentro de su contexto cultural y medioambiental.

\section{Referencias}

Alva, W. (1986). Las Salinas de Chao. Asentamiento temprano en el norte del Perú, Materialien zur Allegemeinen und Vergleichenden Archiiologie Band 34, Verlag C. H. Beck, München.

Bird, E. (2008). Coastal geomorphology. An introduction, 2da. edición, John Wiley \& Sons, New York.

Cárdenas, M. (1976). Informe preliminar del trabajo de campo en el valle de Chao (departamento de la Libertad)Junio de 1976, Seminario de Arqueología, Instituto Riva-Agüero, Pontificia Universidad Católica del Perú, Lima.

Cárdenas, M. (1977-78). Obtención de una cronología del uso de recursos marinos en el antiguo Perú, Boletín del Seminario de Arqueología PUCP 19-20, 3-26.

Cárdenas, M. (1978). Columna cronológica del valle de Chao. Informe general de trabajos, Instituto Riva Agüero, informe no publicado enviado al Instituto Nacional de Cultura-La Libertad, Lima.

Cárdenas, M. (1995). El sitio precerámico de Los Morteros, pampa de Salinas de Chao, Boletín de Lima 100, 45-56.

Cárdenas, M. (1999). El Periodo Precerámico en el valle de Chao, Boletín de Arqueología PUCP 3, 141-169. 
Dillehay, T., D. Bonavia, S. Goodbred, M. Pino, V. Vásquez, T. Rosales, W. Conklin, J. Splitstoser, D. Piperno, J. Iriarte, A. Grobman, G. Levi-Lazzaris, D. Moriera, M. López, T. Tung, A. Titelbaum, J. Verano, J. Adovasio, L. Scott, P. Bearez, E. Dufour, O. Tombret, M. Ramírez, R. Beavins, L. DeSantis, I. Rey, P. Mink, G. Maggard, T. Franco (2012). Chronology, mound-building and environment at Huaca Prieta, coastal Peru, from 13700 to 400 years ago, Antiquity 86, 48-70.

Feldman, R. (1980). Aspero, Peru: Architecture, subsistence economy and other artifacts of a Preceramic Maritime Chiefdom, tesis de doctorado, Harvard University, Cambridge.

Haas, J. y W. Creamer (2006). The crucible of Andean civilization. The Peruvian coast from 3000 to 1800 BC, Current Anthropology 47 (5), 745-775.

Mauricio, A.C. (2014). Los Morteros: Exploraciones Geoarqueológicas y Paleoambientales de un Mountículo Temprano, Valley de Chao, Bulletin de l'Institut Français d'études Andines 43(1), 141-169.

Mauricio, A.C. (2015). Los Morteros: Early Monumentality and Environmental Change in the Lower Chao Valley, Northern Peruvian Coast, PhD dissertation, University of Maine, Orono.

Mauricio, A.C. (2018). El sitio Los Morteros y el complejo arqueológico de Pampa de las Salinas, en: La cooperación francesa en Latinoamérica. Avances recientes en datación y arqueometría en los Andes, 101-118, Instituto Francés de Estudios Andinos, La Paz.

Mauricio, A.C. (2019). Los Morteros, el paleoambiente de Pampa de las Salinas y el desarrollo de la complejidad temprana en el valle de Chao, Costa Norte del Perú, Boletín YUNGAS 3(7), 77-88.

Mauricio, A.C., R. Grieseler, H. Heller, A.R. Kelley, F. Rumiche, D.H. Sandweiss y W. Viveen (2021). The earliest adobe monumental architecture of the Americas, PNAS 118 (48), e2102941118. https://doi. org/10.1073/pnas.2102941118

Moseley, M.E. (1975). The maritime foundations of Andean civilization, Cummings Publishing Company, Menlo Park.

Perrier, C., C. Hillaire-Marcel y L. Ortlieb (1994). Paléogéographie Littorale et enregistrement isotopique (13C, 18O) d'événements de types El Niño par les mollusques Holocénes et récents du nord-ouest péruvien, Geographie Physique et Quaternaire, 48, 23-38.

Pozorski, S. y T. Pozorski (1990). Reexamining the critical Preceramic/ Ceramic Period transition: New data from coastal Peru, American Anthropologist 92, 481-491.

Quilter, J. (1991). Problems with the Late Preceramic of Peru. American Anthropologist, New Series 93 (2), 450 454.

Rollins, H.B., J.B. Richardson III y D.H. Sandweiss (1986). The birth of El Nino: Geoarchaeological evidence and implications. Geoarchaeology: An International Journal 1(1), 3-15.

Sandweiss, D.H. (1986). The beach ridges at Santa, Peru: El Nino, uplift, and prehistory, Geoarchaeology, 1: 17-28.

Sandweiss, D.H., H.B. Rollins y J.B. Richardson III (1983). Landscape alteration and prehistoric human occupation on the north coast of Peru, Annals of Carnegie Museum 52, 277-297.

Shady, R., J. Haas y W. Creamer (2001). Dating Caral, a pre-ceramic site in the Supe Valley on the central coast of Peru, Science 292, 723-726.

Waters, M.R. (1992). Principles of Geoarchaeology: A North American perspective, The University of Arizona Press, Tucson.

Recibido: noviembre 2020

Aceptado: marzo: 2021 